\title{
IMPLICACIÓN DE LA ASTROGLÍA EN EL DAÑO GLAUCOMATOSO
}

\section{IMPLICATIONS OF ASTROGLIA IN GLAUCOMATOUS DAMAGE}

\author{
RAMÍREZ JM ${ }^{1}$, SALAZAR JJ ${ }^{2}$
}

La cabeza del nervio óptico (NO) está constituida por la capa superficial de fibras nerviosas (CSFN), región preliminar (RPL), región de la lámina cribosa (RLC) y región retrolaminar (RRL).

Aunque los axones de las células ganglionares son el elemento fundamental del NO, el resto de los componentes contribuyen a mantener el equilibrio fisiológico que permitirá su adecuado funcionamiento. Entre estos otros componentes celulares cabe destacar a las células astrogliales.

La astroglía cumple distintas funciones según su localización. En la CSFN aíslan a los axones del vítreo y en la región prelaminar dirigen y controlan la ordenación de las fibras nerviosas. Esto se produce por una agrupación especial de los astrocitos que forman cestas al nivel más anterior y tubos al nivel más posterior de la porción preliminar (1).

En la lámina cribosa las células de astroglía revisten los orificios cribiformes y en la región retrolaminar comparten el espacio con las células de oligodedroglía, que a partir de ese momento comienzan a mielinizar los axones (1).

Estructuralmente la lámina cribosa es un tejido complejo que configura múltiples poros por donde han de pasar los axones. El tamaño de estos poros varía entre diez y cien micras. La distribución de los poros es desigual, de manera que en las regiones nasal y temporal del NO son más pequeños y hay más densidad, lo que permite que sean más resistentes. Por el contrario, las regiones superior e inferior del NO tienen menos orificios al ser estos de mayor diámetro, lo que condiciona una menor resistencia.
La lámina cribosa tiene dos componentes, el celular y la matriz extracelular (MEC). El primero está constituido por astrocitos que proporcionan el soporte, contribuyen al mantenimiento del ambiente extracelular y asumen el daño mecánico e isquémico. Todos son GFAP positivos puesto que esa es la proteína que constituye su citoesqueleto, pero a su vez pueden ser NCAM (molécula de adhesión celular neural) positivos si se relacionan con los axones (astrocitos tipo 1B) o NCAM negativos si no se relacionan con ellos (astrocitos tipo 1A). Otras células presentes, aunque no bien conocidas, parecen estar relacionadas con fibroblastos y son GFAP negativas. Por último, están las células de microglía que además de ser GFAP negativas, son positivas para HLA-DR y CD45 $(2,3)$.

El otro componente fundamental de la lámina cribosa, la MEC, está constituida por macromoléculas específicas ensambladas para proporcionar fuerza, flexibilidad y elasticidad al tejido. Entre sus componentes se pueden distinguir colágenos de distinto tipo (I, III, IV, V, VI), elastina, membranas basales filamentosas, dermatán sulfato, condroitín sulfato 4 y 6, ácido hialurónico, decorina, laminina y heparán sulfato.

La importancia de la lámina cribosa se debe a que representa un lugar clave en el mantenimiento del gradiente de presión entre los espacios intra y extraocular, considerándose actualmente como la zona diana del daño glaucomatoso. Además, el estar nutrida solamente por ramas derivadas del círculo de Zinn-Haller (perteneciente al sistema ciliar) hace que pueda ser aún más vulnerable, pues sabemos

\footnotetext{
1 Doctor en Medicina. Catedrático de Oftalmología. Instituto de Investigaciones Oftalmológicas Ramón Castroviejo. Universidad Complutense de Madrid. Madrid. España. Coordinador de la Plataforma «Glaucoma» de la RETICs RD07/0062 (Patología ocular del envejecimiento, calidad visual y calidad de vida)

E-mail: ramirezs@med.ucm.es

2 Doctor en Ciencias Biológicas. Profesor Titular EU. Instituto de Investigaciones Oftalmológicas Ramón Castroviejo. Universidad Complutense de Madrid. Madrid. España. Miembro de la RETICs RD07/0062.

E-mail: jjsalazar@med.ucm.es
} 
que funciona con una presión de perfusión menor que el sistema de la ACR.

La riqueza del contenido celular de la lámina cribosa, tan relacionado con los vasos y axones, permite que tanto un incremento de presión intraocular como una disminución de flujo en el círculo de Zinn-Haller sean capaces de modificar su fisiología, lo que se traduce en una reactivación celular que da lugar a la remodelación de la MEC.

En el glaucoma primario de ángulo abierto, dichos cambios condicionan un incremento del colágeno tipo VI y una disminución de las fibras colágenas alrededor de las fibras elásticas, lo que determina una alteración importante de las propiedades mecánicas a este nivel. Además, el colágeno tipo IV, constituyente de la membrana basal astrocitaria, también se incrementa extraordinariamente en las regiones prelaminar y laminar, modificando la estructura original de los agujeros cribiformes. Si a esto le añadimos la modificación de los proteoglucanos y glucosaminoglucanos, y la degeneración de las fibras elásticas, es tentador pensar que la alteración de las propiedades biomecánicas de la zona podría explicar porqué existe una menor capacidad para amortiguar el gradiente de presión en esta patología (4).

La astroglía, como una de las células más numerosas de la cabeza del NO, cumple funciones clave en el mantenimiento de la fisiología del mismo (1). Por su relación con vasos y axones, puede almacenar glucosa en forma de glucógeno para ser suministrado posteriormente en situaciones de estrés neuronal. Interviene en el mantenimiento del equilibrio iónico del sodio y del potasio y en el metabolismo de neurotransmisores como el glutamato. Produce laminina, fibronectina y tropoelastina, el precursor de la elastina, así como factores de crecimiento entre los que se encuentran: el factor de crecimiento fibroblástico básico (bFGF), el factor de transformación del crecimiento beta (TGF- $\beta$ ) o factores de supervivencia neuronal como el factor del crecimiento nervioso (NGF) (5).

En situaciones de estrés la astroglía se reactiva formando una barrera que aísla el área dañada, separándola de la zona intacta. La condición de reactivación celular se manifiesta por una hipertrofia de la célula, por un incremento de la expresión de GFAP alrededor de los vasos y de N-CAM 180. Además, durante la reactivación se incrementa la integrina $\beta 1$ asociada a los astrocitos, se sintetiza tenascina y aumentan las metaloproteinasas (MMPs) que degradan las moléculas de adhesión permitiendo su movi- lización. Además, la astroglía tiene capacidad para la presentación de antígenos $(2,3)$.

En nuestro laboratorio hemos podido comprobar, tras la provocación de un glaucoma experimental en rata, que a los quince días de enfermedad se produce un aumento de inmunorreactividad para GFAP en aquellas células que se sitúan sobre los vasos. Simultáneamente, se produce una disminución de los astrocitos que se localizan entre los vasos (intervasculares) y la glía de Müller se vuelve inmunorreactiva para GFAP. Al mes y medio de evolución, los astrocitos de la retina periférica han disminuido notablemente y la inmunotinción más intensa para GFAP se observa en los márgenes del disco óptico, lo que hablaría a favor de una movilización celular desde las regiones más anteriores de la cabeza del NO. El aumento de la inmunorreactividad para GFAP en los astrocitos reactivos se corresponde, a microscopía electrónica de transmisión, con un gran incremento de los filamentos gliales que constituyen su citoesqueleto $(6,7)$.

En condiciones normales los astrocitos se comunican entre sí utilizando como neurotransmisor el óxido nítrico (ON), por lo que expresan NOS-1(óxido nítrico sintetasa). En contraste, en situaciones de estrés, bien por aumento de PIO o por isquemia, producen NOS-2 inducible, originando la formación de peroxinitritos y radicales hidroxilo que son tóxicos para los axones (3). A ésta situación tenemos que añadir que el cambio en la geometría celular secundaria a su reactividad, favorece la acumulación en el espacio intercelular de glutamato, $\mathrm{H}^{+}$y $\mathrm{k}^{+}$que posteriormente se introducirán en el citoplasma astrocitario, dando lugar al edema celular. Dicho edema provoca la desinserción de los filamentos intermedios y la muerte astroglial, desprotegiéndose el axón y acabando con la muerte de la neurona. La irreversibilidad de la enfermedad glaucomatosa reside precisamente en la muerte de las células ganglionares, responsables de los campos receptores en la retina.

Por tanto, podemos decir que el colapso de la lámina cribosa no es el inicio de la pérdida de axones sino el resultado del fallo del astrocito en el que se compromete su función de soporte, se alteran sus mecanismos de protección neuronal y se induce un efecto tóxico directo por el aumento de óxido nítrico en el tejido nervioso.

Solo el conocimiento, cada vez más preciso, de los mecanismos que implican a los distintos componentes de la cabeza del nervio óptico nos permitirá esperar, en un futuro próximo, la aparición de 
nuevas terapéuticas, probablemente muy distintas a las que actualmente utilizamos.

\section{BIBLIOGRAFÍA}

1. Triviño A, Ramírez JM, Salazar JJ, Ramírez AI, GarcíaSánchez J. Immunohistochemical study of human optic nerve head astroglia. Vision Res 1996; 36: 2015-2028.

2. Morgan JE. Optic nerve head structure in glaucoma Astrocytes as mediators of axonal damage. Eye 2000; 14: 437-444.

3. Hernandez MR. The optic nerve head in glaucoma: role of astrocytes in tissue remodeling. Prog Retin Eye Res 2000; 19: 297-321.
4. Morrison JC. Integrins in the optic nerve head: potential roles in glaucomatous optic neuropathy (an American Ophthalmological Society thesis).Trans Am Ophthalmol Soc 2006; 104: 453-477.

5. Urban Z, Agapova O, Hucthagowder V, Yang P, Starcher $B C$, Hernandez MR. Population differences in elastin maturation in optic nerve head tissue and astrocytes. Invest Ophthalmol Vis Sci 2007; 48: 3209-3215.

6. Ramírez JM, Salazar JJ, Ramírez AI, de Hoz R, Rojas B, Villegas-Perez MP, et al. Morphometric analysis of the retinal astroglia in an ocular hypertension model. Invest Ophthalmol Vis Sci 2005; 46: E-Abstract 1318.

7. Ramírez AI, Salazar JJ, de Hoz R, Rojas B, Triviño A, Villegas-Perez MP, et al. Behaviour of glia in a model of chronic ocular hypertension. Ophthalmic Res 2005; 37: 32 . 